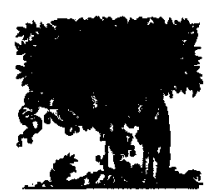

ELSEVIER

\title{
Bistability and oscillations of the NO/CO reaction on a Pt-Mo supported catalyst
}

\author{
Brigitta Frank $^{\mathrm{a}}$, Ralf Doepper ${ }^{\mathrm{a}}$, Gerhard Emig ${ }^{\mathrm{b}}$, Albert Renken ${ }^{\mathrm{a}, *}$ \\ ${ }^{a}$ Institute of Chemical Engineering, Swiss Federal Institute of Technology, CH-1015 Lausanne, Switzerland \\ ${ }^{\mathrm{b}}$ Lehrstuhl für Technische Chemie l, Universität Erlangen-Nürnberg, D-91058 Erlangen, Germany
}

\begin{abstract}
The reaction of nitric oxide with carbon monoxide on a catalyst of $0.5 \mathrm{wt} \% \mathrm{Pt}-3.4 \mathrm{wt} \% \mathrm{MoO}_{3}$ supported on $\alpha$ - $\mathrm{Al}{ }_{2} \mathrm{O}_{3}$ has been investigated in different reactors at atmospheric pressure. A fixed-bed reactor with external recycle loop exhibited bistability and hysteresis as $\mathrm{CO}$ concentration or temperature were varied. In a tubular fixed-bed reactor non-isothermal periodic oscillations $\left(\Delta T_{\max }=40 \mathrm{~K}\right)$ were found in a specific pressure-concentration-temperature region $(p-c-T$ region). The amplitude and period time of the oscillations changed smoothly inside the $p-c-T$ region and died out suddenly at the borders of the region. The oscillations were of a relaxation type and lasted for more than $48 \mathrm{~h}$. With fresh catalyst, a new quartz reactor and a specific pretreatment they were reproducible. It was shown that oscillations had kinetic origins and that the changes of the temperature synchronised the elementary oscillators. An autocatalytic model is proposed to explain the experimentally observed phenomena.
\end{abstract}

Keywords: Nitric oxide; Carbon monoxide; Pt-Mo supported catalyst; Bistability; Oscillations

\section{Introduction}

In continuous flow systems where reactions with strongly non-linear reaction kinetics take place, bistability and oscillations are found. The causes and effects of such stationary or dynamic instabilities of systems far away from equilibrium has been a large field of research in the last 25 years [1].

The commonly known example for bistability is the cooled continuously stirred tank reactor (CSTR) where a highly exothermic homogeneous reaction leads to ignition and extinction of the reaction [2]. Ignition is a transition from a kinetic to a transport

\footnotetext{
*Corresponding author. Tel.: (41-21) 693-3181; Fax: (41-21) 693-3190; e-mail: renken@igcsun3.epfl.ch
}

controlled region and extinction the transition back to the kinetic controlled region.

Besides such thermal instabilities where the nonlinearity of the reaction has thermal causes, isothermal bistability can arise if reaction rate passes a maximum with increasing concentration of a reactant (self-poisoning) or a product (autocatalytic behaviour) [3]. In this case multistability can arise if three stationarystate compositions exist for the same rate constants, inlet concentrations and flow rate. In practice only two of the stationary-state compositions are accessible; consequently this type of response is called bistability.

Closely connected to the phenomenon of bistability is the appearance of oscillations. If an appropriate feedback mechanism is present in a bistable system, oscillations arise for certain conditions. In this case a 
parameter of a bistable system may become a variable changing slowly under the influence of the feedback mechanism towards a point where a rapid change takes place. The arising oscillations are of a relaxation type, which means that one period of the oscillations can be divided in several characteristic parts corresponding to slow and fast changes of the variable.

In heterogeneous catalysis non-isothermal and isothermal bistability and oscillations have been found [4]. Experimental evidences of bistability and isothermal oscillations were given for the first time by Wicke and coworkers $[5,6]$ on single catalyst particles and by Hugo and Jakubith [7] in a recycle reactor, both for the $\mathrm{CO} / \mathrm{O}_{2}$ reaction on $\mathrm{Pt}$.

Since these early works many investigations have been made under high vacuum conditions on single crystal surfaces in order to study the molecular mechanism of oscillations [8]. A recent review about oscillations in heterogeneous catalysis is given by Slin'ko and Jaeger [9].

Several models were developed to explain the appearance of oscillations, but even for the $\mathrm{CO} / \mathrm{O}_{2}$ reaction on $\mathrm{Pt}$, which is the mostly studied reaction, no commonly accepted model exists which is applicable for single crystal surfaces and for supported catalysts.

To advance in the understanding of kinetic oscillations more detailed data also of other reactions has to be considered and further efforts have to be undertaken to discriminate between different models and to develop models which are also applicable for supported catalysts.

The NO/CO reaction on $\mathrm{Pt}$ has been less investigated as the $\mathrm{CO} / \mathrm{O}_{2}$ reaction and a list of publications is shown in Table 1. Most of the studies were low pressure studies, on supported catalysts at atmospheric pressure only three publications were found:

Subramaniam and Varma [12] observed isothermal aperiodic oscillations in the $\mathrm{CO} / \mathrm{NO} / \mathrm{O}_{2} / \mathrm{H}_{2} \mathrm{O}$ system on $0.1 \% \mathrm{Pt} / \gamma-\mathrm{Al}_{2} \mathrm{O}_{3}$ and Regalbuto and Wolf [15] nonisothermal aperiodic oscillations of the reaction $\mathrm{NO} /$ $\mathrm{CO} / \mathrm{O}_{2}$ on $5 \% \mathrm{Pt} / \gamma-\mathrm{Al}_{2} \mathrm{O}_{3}$. Periodic oscillations of $\mathrm{NO} / \mathrm{CO}$ on a supported catalyst were found by Schüth and Wicke [17]. They reported relaxation oscillations from $350^{\circ} \mathrm{C}$ to $470^{\circ} \mathrm{C}$ with concentrations of $10 \% \mathrm{NO}$ and $2.5-12 \% \mathrm{CO}$ on $1-5 \% \mathrm{Pt} / \gamma-\mathrm{Al}_{2} \mathrm{O}_{3}$ or $\mathrm{SiO}_{2}$.

In the present paper the reaction of $2 \% \mathrm{NO}$ and 0 $1.8 \% \mathrm{CO}$ was for the first time examined on a $0.5 \mathrm{wt} \%$ $\mathrm{Pt}-3.4 \mathrm{wt} \% \mathrm{MoO}_{3}$ catalyst supported on $\alpha-\mathrm{Al}_{2} \mathrm{O}_{3}$. The following two reactions can take place in this system (Eqs. (1) and (2)), $\mathrm{N}_{2} \mathrm{O}$ does not further react with $\mathrm{CO}$ as was confirmed in separate experiments.

$$
\begin{aligned}
& 2 \mathrm{NO}+2 \mathrm{CO} \rightarrow \mathrm{N}_{2}+2 \mathrm{CO}_{2} \\
& 2 \mathrm{NO}+\mathrm{CO} \rightarrow \mathrm{N}_{2} \mathrm{O}+\mathrm{CO}_{2}
\end{aligned}
$$

Bistable behaviour and oscillations were found in different reactors and a model, which was developed for oscillations on single crystal surfaces, is proposed to explain the observed behaviour at atmospheric pressure.

Table 1

\begin{tabular}{|c|c|c|c|c|c|c|}
\hline Authors & Year & Catalyst & Pressure range & Temperature $\left({ }^{\circ} \mathrm{C}\right)$ & $c_{\mathrm{NO}} / c_{\mathrm{CO}}$ & Reference \\
\hline Singh-Boparai, King & 1980 & $\operatorname{Pt}(100)$ & $5 \times 10^{-9}$ & 30 & & {$[10]$} \\
\hline Adlhoch, Lintz, Weisker & 1981 & Polycrystalline $\mathrm{Pt}$ ribbon & $<5 \times 10^{-4}$ torr & $190-250$ isothermal & $1-4$ & [11] \\
\hline Subramaniam, Varma & 1983 & $\begin{array}{l}0.1 \% \mathrm{Pt} / \gamma-\mathrm{Al}_{2} \mathrm{O}_{3} \\
\mathrm{NO}+\mathrm{CO}+\mathrm{O}_{2}+\mathrm{H}_{2} \mathrm{O}\end{array}$ & 1 bar & $380-600$ isothermal & & {$[12]$} \\
\hline Klein & 1985 & Polycrystalline $\mathrm{Pt}$ & $0.1-1$ torr & 430 & & in Ref. [13] \\
\hline Bolten, Hahn, LeRoux, Lintz & 1985 & Polycrystalline $\mathrm{Pt}$ & $4 \times 10^{-4} \mathrm{mbar}$ & $230-255$ & & [14] \\
\hline Regalbuto, Wolf & 1986 & $\begin{array}{l}5 \% \mathrm{Pt} / \mathrm{SiO}_{2} \\
\mathrm{NO}+\mathrm{CO}+\mathrm{O}_{2}\end{array}$ & 1 bar & $\begin{array}{l}250( \pm 110 \mathrm{~K}) \\
\text { non-isothermal }\end{array}$ & & {$[15]$} \\
\hline Schwartz, Schmidt & 1987 & $\operatorname{Pt}\left(\begin{array}{lll}1 & 0 & 0\end{array}\right)$ & $10^{-6}-10^{-7}$ torr & $130-220$ isothermal & $1-2$ & {$[13,16]$} \\
\hline Schüth, Wicke & 1989 & $\begin{array}{l}1-5 \% \mathrm{Pt} / \mathrm{SiO}_{2} \text { or } \\
\mathrm{Pt} / \gamma-\mathrm{Al}_{2} \mathrm{O}_{3}\end{array}$ & 1 bar & $\begin{array}{l}350-470( \pm 25 \mathrm{~K}) \\
\text { non-isothermal }\end{array}$ & $0.8-4$ & {$[17]$} \\
\hline Schmidt, Aris & 1990 & $\operatorname{Pt}\left(\begin{array}{lll}1 & 0 & 0\end{array}\right)$ & $10^{-8}$ torr & $140-190$ isothermal & $1-2$ & [18] \\
\hline Fink, Dath, Imbihl, Ertl & 1991 & $\operatorname{Pt}\left(\begin{array}{llllll}1 & 0 & 0\end{array}\right)$ & $10^{-7}$ torr & 130 & 1.2 & {$[19]$} \\
\hline Veser, Imbihl & 1994 & $\operatorname{Pt}\left(\begin{array}{lll}1 & 0 & 0\end{array}\right)$ & $10^{-6}$ mbar & $205-217$ & 1 & {$[20,21]$} \\
\hline
\end{tabular}

Reported oscillations for the NO/CO reaction on Pt catalysts 


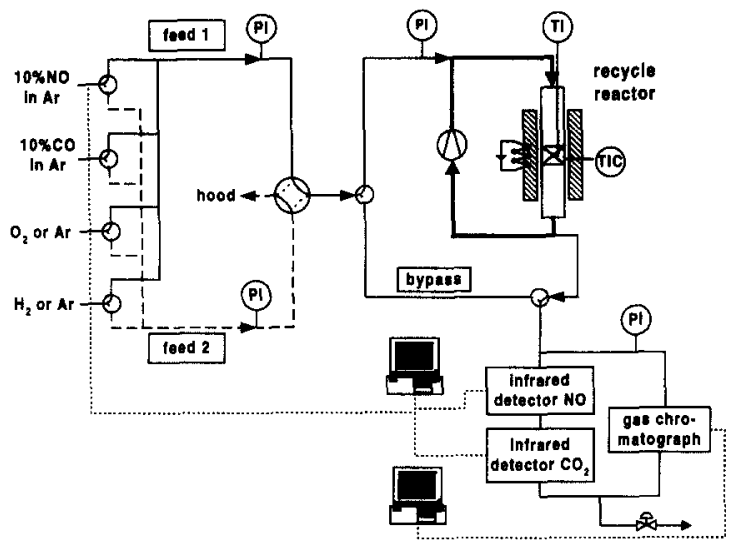

Fig. 1. Scheme of the experimental set-up with a recycle reactor.

\section{Experimental}

\subsection{Apparatus}

The experimental set-up is shown in Fig. 1 and consists of three parts: gas supply, the reactor and the analysis part. As gases $\mathrm{CO}$ and $\mathrm{NO}(10 \%$ in $\mathrm{Ar})$, $\mathrm{O}_{2}, \mathrm{H}_{2}$ and $\mathrm{Ar}$ were used with purities of $>99.996 \%$ (NO 99.9\%) without further treatment (Carbagas, $\mathrm{CH})$. Gases were supplied by mass flow controllers (F-201, Bronkhorst, The Netherlands) and could be directed to two different feeds. A four-way valve directed one of the feeds to the reactor and the other to the hood and permitted to switch between the two feeds.

Two different reactors were used: Shown in Fig. 1 is the continuous fixed-bed reactor with external recycle loop used for the studies of the bistable behaviour, a tubular fixed-bed reactor without recycling was used for the measurements of oscillations. Both reactors consisted of a quartz tube (recycle reactor $d_{\mathrm{i}}=10 \mathrm{~mm}$, tubular fixed-bed reactor $d_{\mathrm{i}}=5 \mathrm{~mm}$ ), in which the catalyst was held by some quartz wool. In front of the catalyst a bed of glass beads $(d=1 \mathrm{~mm})$ of a height of $3 \mathrm{~cm}$ assured a better distribution of the gas flow. In the case of the recycle reactor a membrane compressor (KNF Neuberger, Germany) to recycle the gas volume was used and since the recycle ratio did not fall short of 30 (conversions were from $0-40 \%$ ), the reactor can be considered as a continuous stirred tank reactor (CSTR). Volumetric flow rate inside the recycle loop was calculated from the pressure drop in a $300 \mathrm{~mm}$ stainless steel tube ( $d=\frac{1}{4}$ in.) which was measured by a glass U-tube filled with dibutyl phthalate.

Reaction zone was heated by four heating cartridges (Vulkan, Switzerland) introduced in a block of stainless steel $(h=140 \mathrm{~mm}, d=50 \mathrm{~mm})$ and kept at the desired temperature by an external PID regulator (Eurotherm, UK). The temperature inside the reactor was measured by separate thermocouples (K-type, Philips, Switzerland). For the recycle reactor a movable thermocouple $(d=1 \mathrm{~mm})$, protected by a glass capillary, went through the middle of the catalyst bed. For the tubular fixed-bed reactor a $0.5 \mathrm{~mm}$ thermocouple was introduced in the catalyst bed.

The reactor effluent was measured by a gas chromatograph (Fisons GC 8000, Brechbühler, Switzerland) and two infrared detectors for $\mathrm{NO}$ and $\mathrm{CO}_{2}$ (Ultramat $5 \mathrm{E}$ et $22 \mathrm{P}$, Siemens, Germany). The gas chromatograph equipped with a thermal conductivity detector was operated at $35^{\circ} \mathrm{C}$ with helium as carrier gas. Separation of all gases $\left(\mathrm{N}_{2} \mathrm{O}, \mathrm{CO}_{2}, \mathrm{Ar}, \mathrm{N}_{2}, \mathrm{NO}\right.$ and $\mathrm{CO}$ ) was realised with two consecutive columns and a four-way valve in between them (1st column: Porapak $S, l=15 \mathrm{ft}, d=\frac{1}{8}$ in., $80 / 100$ mesh; 2nd column: Molecular Sieve 5A, $l=4 \mathrm{~m}, d=\frac{1}{4}$ in., 60/80 mesh). Ar, $\mathrm{N}_{2}, \mathrm{NO}$ and $\mathrm{CO}$ were not separated on the 1 st column and passed quickly to the 2 nd column. In this moment the valve turned so that $\mathrm{CO}_{2}$ and then $\mathrm{N}_{2} \mathrm{O}$ were eluated from the 1st column. The valve turned again and $\mathrm{Ar}, \mathrm{N}_{2}, \mathrm{NO}$ and $\mathrm{CO}$, respectively were eluated from the 2 nd column.

The analysis time was $52 \mathrm{~min}$ and chromatograms were directly recorded on a computer. A second computer recorded temperature and infrared signals and regulated the mass flow controllers if they were not manually regulated.

During experiments with varying temperatures or CO concentrations each point was kept constant for 260 min corresponding to five chromatograms (except in the experiment of Fig. 7). For purge experiments $250 \mathrm{ml} / \mathrm{min}$ of the reaction mixture was changed against $25 \mathrm{ml} / \mathrm{min}$ pure argon at $t=0$ by switching the four-way valve between the two feeds.

\section{Catalyst}

A catalyst containing $0.5 \mathrm{wt} \% \mathrm{Pt}-3.4 \mathrm{wt} \% \mathrm{MoO}_{3}$ supported on grains of $\alpha-\mathrm{Al}_{2} \mathrm{O}_{3}$ with a diameter 
1-1.25 mm was used for all experiments. The catalyst was prepared by a dry impregnation technique: The support was degassed in a rotavapour and the necessary amount of an aqueous platinum-chloride solution was added. It was dried for $2 \mathrm{~h}$ at $200^{\circ} \mathrm{C}$ before adding an ammonium-paramolybdate solution, after which a calcination for $2 \mathrm{~h}$ at $500^{\circ} \mathrm{C}$ was carried out.

Apparent density of the catalyst was $3970 \mathrm{~kg} / \mathrm{m}^{3}$ and the BET surface was about $2-2.5 \mathrm{~m}^{2}$. The catalyst was macroporous with a mean pore diameter of $200 \pm 10 \mathrm{~nm}$ measured by mercury penetration method. Calculations of the Weisz criteria [22] revealed that internal transfer limitations were not present. External transport limitations, calculated with the criteria of Mears [22], could only be excluded for the recycle reactor but not for the fixed-bed reactor.

New catalyst was reduced for $1.5 \mathrm{~h}$ with $10 \% \mathrm{H}_{2}$ at $400^{\circ} \mathrm{C}$ and treated for $16 \mathrm{~h}$ with $2 \% \mathrm{NO}$ and $1 \% \mathrm{CO}$ at $450^{\circ} \mathrm{C}$. For some experiments, where it is mentioned in the text, a more rigorous pretreatment was used, where the catalyst was oxidised $\left(10 \% \mathrm{O}_{2}, 400^{\circ} \mathrm{C}, 2 \mathrm{~h}\right)$ and then reduced and treated as mentioned above.

\section{Results for the recycle reactor}

\subsection{Influence of $\mathrm{CO}$ concentrations and temperature}

The reaction rate of carbon monoxide for different CO concentrations at several temperatures is shown in Fig. 2, where NO concentration is kept constant to $0.28 \mathrm{~mol} / \mathrm{m}^{3}$, volume rate about $300 \mathrm{ml} / \mathrm{min}$ (NTP: $T=273 \mathrm{~K}, p=1.013 \mathrm{bar}$ ).

At $380^{\circ} \mathrm{C}$ the reaction rate of $\mathrm{CO}$ increases with $\mathrm{CO}$ concentration up to $0.11 \mathrm{~mol} / \mathrm{m}^{3}$ (upper operating state). The reaction order in this region is nearly 1 for $\mathrm{CO}$ which corresponds to the well-known formal reaction kinetics of the $\mathrm{CO}$ oxidation on noble metals (p. 10 in Ref. [9]). For a CO concentration of 0.12 the reaction rate fell by a factor of 10 and a stable point could only be obtained for $0.18 \mathrm{~mol} / \mathrm{m}^{3} \mathrm{CO}$ (lower operating state). The conversion remained low upon further increase of the $\mathrm{CO}$ concentration. The extinction of the reaction took in general about $20 \mathrm{~h}$, but could take up to $20 \mathrm{~h}$. Thus for certain CO concentrations no stable points exist and the reaction curve

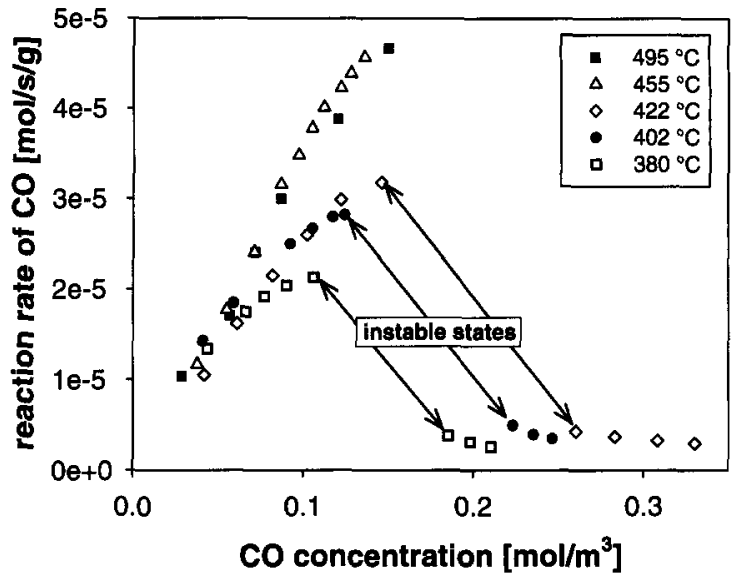

Fig. 2. Stable points for the NO/CO reaction in a recycle reactor on $0.017 \mathrm{~g} 0.5 \% \mathrm{Pt}-3.4 \% \mathrm{MoO}_{3} / \alpha-\mathrm{Al}_{2} \mathrm{O}_{3}$ for increasing $\mathrm{CO}$ concentrations. NO mole fraction was regulated at the outlet of the reactor and NO concentration was of $0.28 \mathrm{~mol} / \mathrm{m}^{3}$.

possesses a region of instable states as indicated in Fig. 2.

The extinction was shifted to higher $\mathrm{CO}$ concentrations when temperature increased, as can be seen by a comparison of the results at $380^{\circ} \mathrm{C}$ with $402^{\circ} \mathrm{C}$ and $422^{\circ} \mathrm{C}$. At higher temperatures extinction is shifted towards $c_{\mathrm{NO}} / c_{\mathrm{CO}}=1$ and occurs only at $0.16 \mathrm{~mol} / \mathrm{m}^{3}$ $\mathrm{CO}$ for $422^{\circ} \mathrm{C}$.

The reaction rate of the upper operating state increased with temperature except for high temperatures, where it remained more or less constant. This can be explained by a decrease in the coverage of the adsorbed species at higher temperatures.

$\mathrm{CO}$ conversions when temperature was varied can be seen in Fig. 3 for $2 \% \mathrm{NO}, 1 \% \mathrm{CO}$ and a volume rate of $100 \mathrm{ml} / \mathrm{min}$ (NTP). For $1 \mathrm{~g}$ catalyst ignition occurred at $310^{\circ} \mathrm{C}$ and $\mathrm{CO}$ conversion passed from $20 \%$ to $100 \%$ within $15 \mathrm{~K}$. For decreasing temperatures extinction took place at a lower temperature $\left(290^{\circ} \mathrm{C}\right)$, thus a hysteresis of the conversion results as the gas temperature varied. By diminishing the mass of the catalyst by a factor of 60 the hysteresis was shifted to higher temperatures and was getting smaller, but was still present as demonstrated in Fig. 3.

To explain the isothermal bistability of a CSTR the mass balance equation has to be considered (Eq. (3)).

$\dot{V} / m_{\mathrm{cat}}\left(c_{\mathrm{CO}}^{0}-c_{\mathrm{CO}}\right)=-R_{\mathrm{CO}}$, 


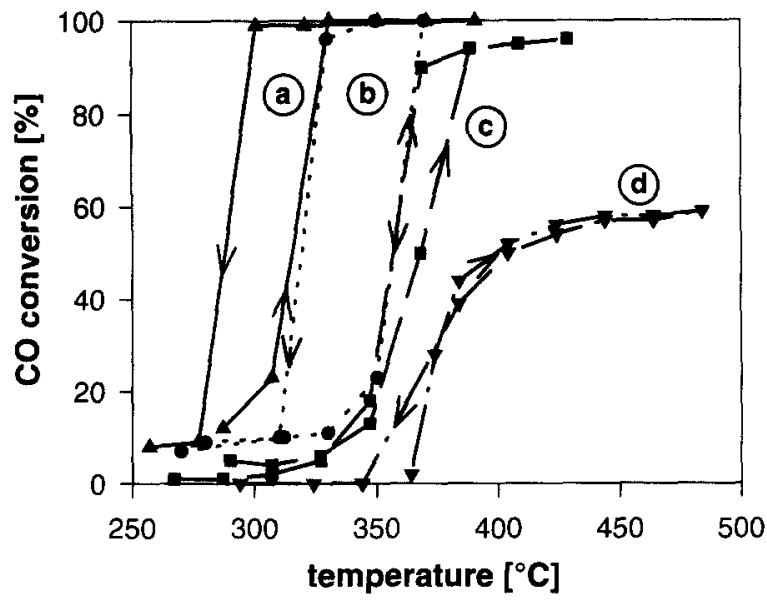

Fig. 3. Hysteresis of the $\mathrm{NO} / \mathrm{CO}$ reaction with temperature in a recycle reactor with different amounts of catalyst: (a) $1 \mathrm{~g}$, (b) $0.5 \mathrm{~g}$, (c) $0.1 \mathrm{~g}$, (d) $0.017 \mathrm{~g}$.

where $c_{\mathrm{CO}}^{0}$ and $c_{\mathrm{CO}}$ are the inlet and outlet concentrations of $\mathrm{CO}\left(\mathrm{mol} / \mathrm{m}^{3}\right)$, respectively, $-R_{\mathrm{CO}}$ the reaction rate of $\mathrm{CO}(\mathrm{mol} / \mathrm{s} \mathrm{g}), \dot{V}$ the volumetric flow rate $\left(\mathrm{m}^{3} / \mathrm{s}\right)$ and $m_{\text {cat }}$ the mass of the catalyst $(\mathrm{g})$. Consequently $\dot{V} / m_{\text {cat }}$ is the reciprocal value of a modified residence time $\left(\mathrm{m}^{3} / \mathrm{g} \mathrm{s}\right)$.

If the consumption by reaction (right-hand side of Eq. (3)) balances exactly the net inflow rate (left-hand side of Eq. (3)) Eq. (3) has a solution corresponding to a stationary state. A first-order reaction has exactly one solution for each $\mathrm{CO}$ concentration resulting in unique steady states. When Eq. (3) has three solutions a region of multistability exists, which is depicted graphically in Fig. 4 where the reaction rate and the net inflow rate have the intersection points 1,2 and 3 at $410^{\circ} \mathrm{C}$. The lowest intersection point 1 and the uppermost intersection point 3 are stable, whereas 2 is not stable. A small increase of reaction rate at this point will lower the $\mathrm{CO}$ concentration. As the supply of $\mathrm{CO}$ is inferior to the consumption by the reaction, $\mathrm{CO}$ will continue to drop until stable point 3 is reached. Similar considerations can be made for a small decrease in reaction rate, where $\mathrm{CO}$ concentration increases until the system approaches the stable point 1 .

Hysteresis of the reaction rate with temperature can be understood in the following way: At $400^{\circ} \mathrm{C}$ only one intersection point exists for an inlet $\mathrm{CO}$ concentration of $1.6 \mathrm{~mol} / \mathrm{m}^{3}$ (point 4) and reaction rate will be low. If the temperature is increased to $410^{\circ} \mathrm{C}$ reaction

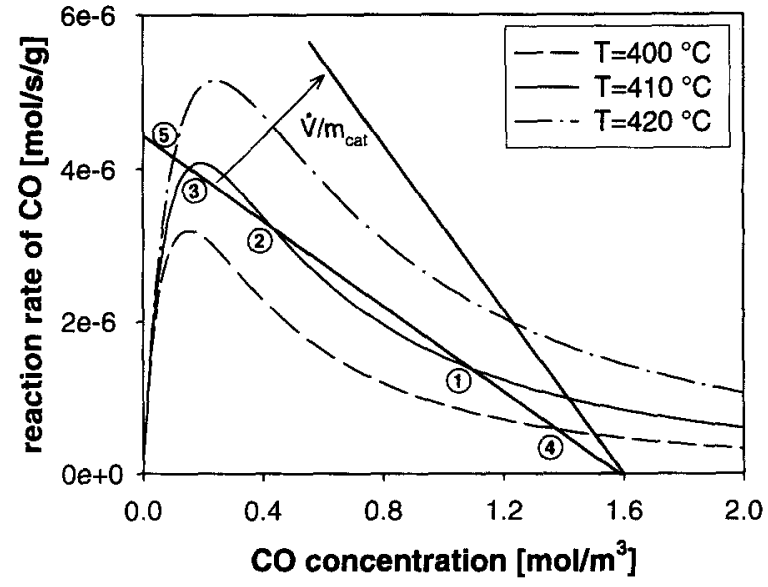

Fig. 4. Graphic solution of the mass balance equation of a CSTR: Intersection of a theoretical non-linear reaction rate (calculated with a Langmuir-Hinshelwood-like model Eq. (4)) and the linear net inflow rate with the slope $\dot{V} / m_{\text {cat }}$ for different temperatures.

rate will rise and the stable point 1 is reached. For $420^{\circ} \mathrm{C}$ only one intersection at a high reaction rate exists, thus the system ignites (point 5 ). By reducing the temperature again to $410^{\circ} \mathrm{C}$ will result in point 3 and for $400^{\circ} \mathrm{C}$ extinction of the reaction occurs and the system will end up in point 4 . Note that ignition occurs at a higher temperature than extinction as observed in experiments.

\section{Results for the tubular fixed-bed reactor}

A tubular fixed-bed reactor was used to examine kinetics of the reaction in the region of instable states of the recycle reactor. This type of reactor does not have a single net inflow rate as a CSTR and consequently a bistability of the reactor as for the CSTR cannot occur and stable points should be obtained for all $\mathrm{CO}$ concentrations.

\subsection{Influence of $\mathrm{CO}$ concentrations and temperature}

For inlet $\mathrm{CO}$ mole fractions $\left(y_{\mathrm{CO}}^{0}\right)$ up to $0.7 \%$ increasing $\mathrm{CO}$ concentrations raised the conversion and measured points were stationary at $T_{\text {regulated }}=$ $370^{\circ} \mathrm{C}$. For $0.8 \% \mathrm{CO}$, when $c_{\mathrm{NO}} / c_{\mathrm{CO}}$ was 2.5 oscillations appeared, which is demonstrated in the bifurcation diagram in Fig. 5. The arrows at $0.8 \% \mathrm{CO}$ 


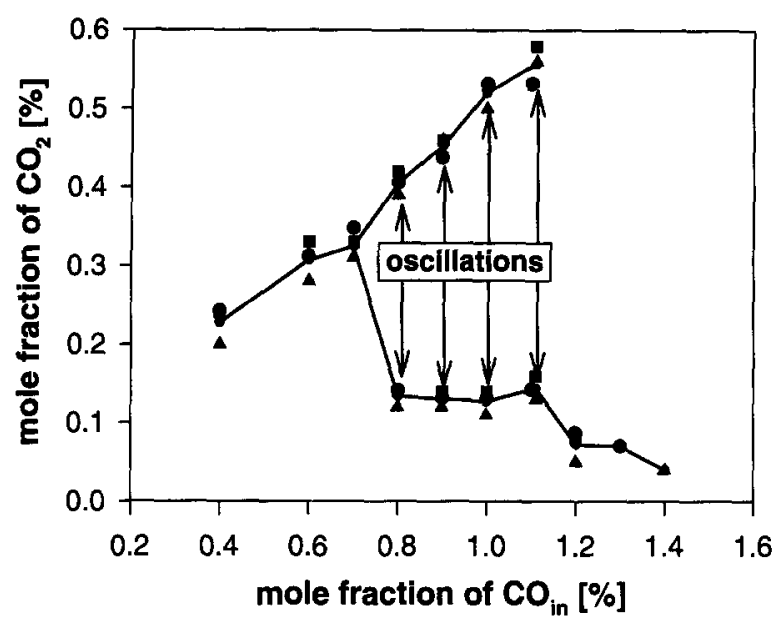

Fig. 5. Bifurcation diagram of the NO/CO reaction on $0.017 \mathrm{~g}$ of a $\mathrm{Pt}-\mathrm{Mo} / \alpha-\mathrm{Al}_{2} \mathrm{O}_{3}$ catalyst in a tubular fixed-bed reactor for three different experiments. Effect of $\mathrm{CO}$ concentration (2\% NO, $T_{\text {regulated }}=370^{\circ} \mathrm{C}$ ).

indicate the maximum and minimum values of the oscillations. The amplitude of the oscillations increased with increasing $\mathrm{CO}$ concentrations, the same tendency was observed by Schüth and Wicke [17] for a Pt supported catalyst. For high CO concentrations oscillations disappeared suddenly and the lower operating state was reached.

The response of the $\mathrm{CO}_{2}$ infrared detector for different molar fractions of $\mathrm{CO}$ is depicted in Fig. 6. The oscillations are of a relaxation type and one can distinguish four sections during one period: slow ignition, fast ignition, upper operating state and fast extinction. Sometimes small damped oscillations appeared just before the $\mathrm{CO}$ concentration where oscillations begin ( $0.7 \% \mathrm{CO}$ in Fig. 6). Probably the synchronisation is not high enough for this $\mathrm{CO}$ concentration.

Oscillations were very stable and continued for more than two days. NO concentration oscillated exactly in counter phase with $\mathrm{CO}_{2}$ and temperature in phase. Temperature changes were important and could be as high as $40 \mathrm{~K}$, thus oscillations were nonisotherm.

An original record of an experiment where temperature was changed is shown in Fig. 7. It can clearly be seen that the amplitude increases with temperature. Other authors found smaller amplitudes at higher temperatures [17], which corresponds to theoretical

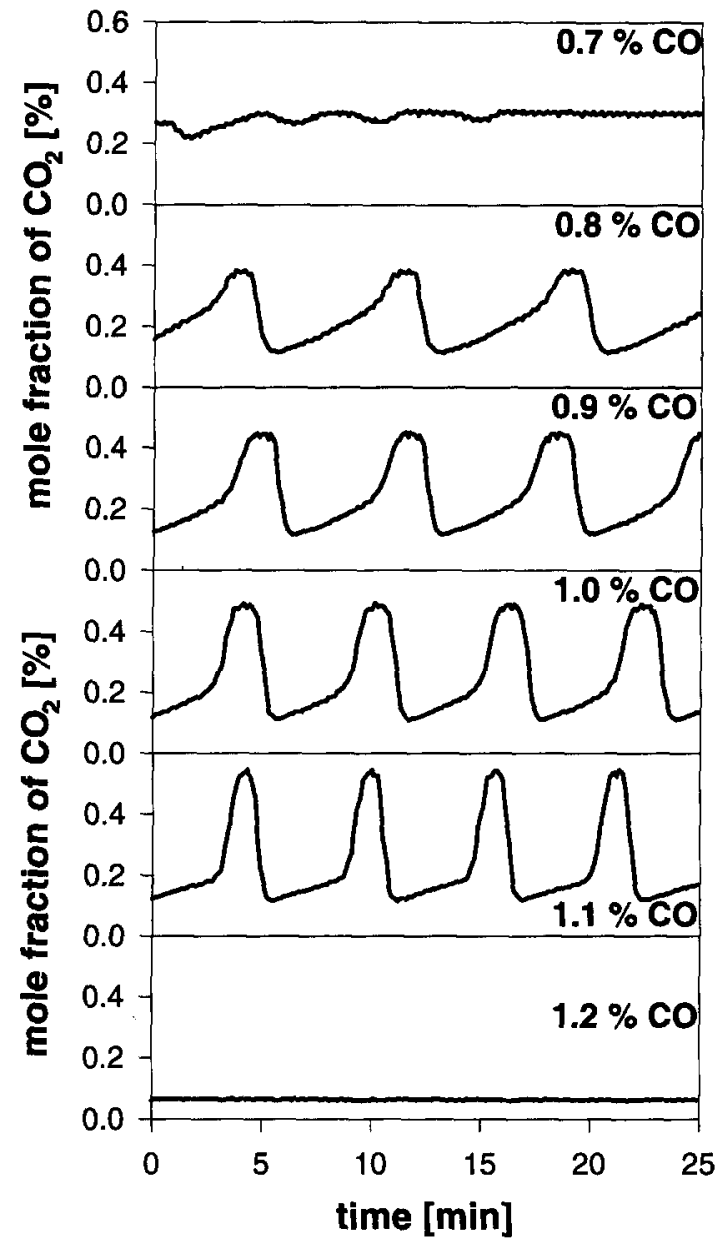

Fig. 6. Oscillations for increasing $\mathrm{CO}$ inlet molar ratios for $2 \%$ NO and $T_{\text {average }}=375^{\circ} \mathrm{C}$.

expectations. It is assumed that in this study the negative influence of the temperature on the amplitude of oscillations is over-compensated by the synchronising effect of the temperature.

Period lengths of observed oscillations were 5$10 \mathrm{~min}$ and decreased with increasing $\mathrm{CO}$ concentrations and temperatures. A decrease with $\mathrm{CO}$ concentration is rather unusual compared to results of other authors (e.g., p. 72 in Ref. [9]; Ref. [17]). It could simply be explained by the temperature increase at higher $\mathrm{CO}$ concentrations which results in a decrease in period time.

For low temperatures $\left(T=360^{\circ} \mathrm{C}\right.$ for $t=175$ $230 \mathrm{~min}$ ) period length increases until the oscillations disappear, for high temperatures $\left(T=421^{\circ} \mathrm{C}\right.$ for 

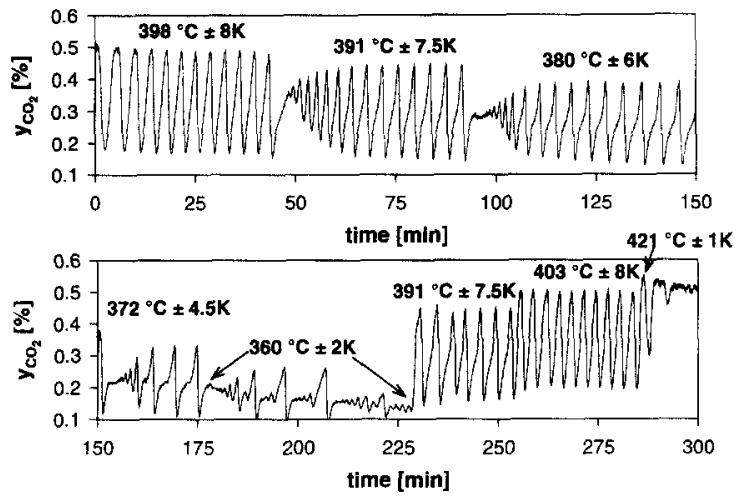

Fig. 7. Original record of oscillations for $2 \% \mathrm{NO} / 1.1 \% \mathrm{CO}$ for different temperatures (mean temperature $t$ half of the temperature amplitude).

$t=285 \mathrm{~min}$ ) oscillations were damped and disappeared rather quickly.

\subsection{Region of oscillations}

Oscillations appeared for all temperatures in the region of instable states of the recycle reactor as can be seen in Fig. 8. The two lines represent the borders of the region of instable states of the recycle reactor and the points obtained result in the tubular fixedbed reactor: circles for oscillations and triangles for stationary states.

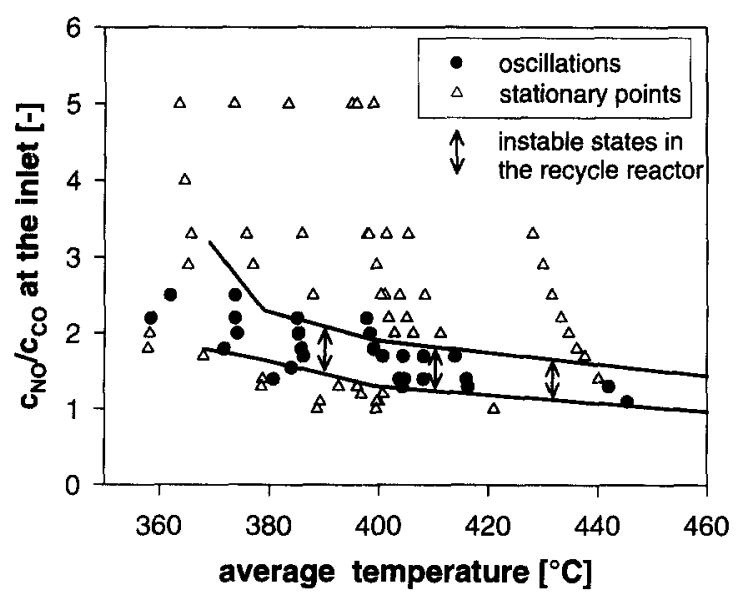

Fig. 8. Oscillations and stationary points in the tubular fixed-bed reactor. Comparison with the region of instable states of the recycle reactor.
One can see that the region of instable states and thus oscillations shift from oxidising atmosphere $\left(c_{\mathrm{NO}} / c_{\mathrm{CO}}=2.5\right.$ ) to $c_{\mathrm{NO}} / c_{\mathrm{CO}}=1$ for higher temperatures. The temperature region where oscillations were found corresponds surprisingly good with the temperature region where Schüth and Wicke ([17], their Fig. 2) found oscillations, although they used another support and other concentrations: $T=370-470^{\circ} \mathrm{C}$ with $c_{\mathrm{NO}} / c_{\mathrm{CO}}=3.9-0.9$.

\subsection{Reproducibility}

It is in general difficult to reproduce oscillations because of their high sensibility to contaminations [13] and the inhomogeneity of the surface especially of supported catalysts where no defined cleaning procedures exist (pp. 67, 74 in Ref. [9]).

In this study oscillations could be reproduced by using the following procedure: a new quartz reactor and a new catalyst had to be taken and a rigorous pretreatment was applied which consisted of an oxidation to eliminate contaminations on the catalyst, a reduction and a subsequent treatment over night at $450^{\circ} \mathrm{C}$ with $2 \% \mathrm{NO}$ and $1 \% \mathrm{CO}$. Increasing $\mathrm{CO}$ concentrations resulted then in oscillations which corresponded in their form, amplitude (Fig. 5) and period time.

Changing the pretreatment - either only oxidation or oxidation/reduction - led to different forms of oscillations which were no more reproducible.

If the thermocouple was introduced in the catalyst bed from above instead of below (gas flow being downwards) small contaminations which were probably liberated from the thermocouple inhibited the oscillations very strongly.

\subsection{Origin of oscillations}

Slin'ko and Jaeger [9] distinguish between three kinds of non-isothermal oscillations occurring on different levels of the catalytic system and having different origins:

1. Non-isothermal kinetic oscillations take place on the level of a single catalyst pellet because of the interplay of adsorption or desorption with a nonlinear reaction rate (NLR). 
2. Complex thermokinetic oscillations take place on the level of the catalyst bed because of the interplay of the transport to the catalyst surface with a NLR.

3. Thermokinetic reactor oscillations take place on the level of the whole reactor because of the interplay of the transport in the reactor with a NLR.

Thermokinetic reactor oscillations can in principle not be found in heterogeneous reactors, where heat storage is much larger than mass storage, but only in homogeneous reactors where heat and mass storage are of the same order of magnitude.

It was shown by calculations and by the overheating of the catalyst bed that in the presented reactor external heat transfer limitations exist, consequently it cannot a priori be decided if the arising oscillations are: (1) kinetic non-isothermal oscillations or (2) complex thermokinetic oscillations. Although the appearance of these two kinds of oscillations is similar, their origin is completely different.

Complex thermokinetic oscillations arise because the limited heat transport leads to large temperature changes, which cause activation and deactivation of the catalyst. A possible mechanism is, e.g. an oxidation of the catalyst at high temperatures that deactivates the catalyst, so that the temperature decreases combined with a subsequent reduction at low temperatures, which activates the catalyst, causing again an increase of the temperature. As the temperature changes are the origin of the complex thermokinetic oscillations, they cannot arise without significant temperature changes, quite in contrary to non-isothermal kinetic oscillations, which can also have smaller or no temperature changes at all. These have their origin in changes of adsorbate coverages which activate or deactivate the catalyst and the temperature changes are only a consequence of the activation/deactivation processes of the catalyst, if heat transfer is not sufficient.

The question is therefore if the oscillations arise because of the temperature changes (complex thermokinetic oscillations) or if they arise because of changes which happen on the molecular level and the temperature only follows the changes in activity (nonisothermal kinetic oscillations). To decide this, $0.017 \mathrm{~g}$ of the catalyst was crushed and diluted with glass beads to ensure isothermal conditions. For some $\mathrm{CO}$ concentrations aperiodic oscillations with small

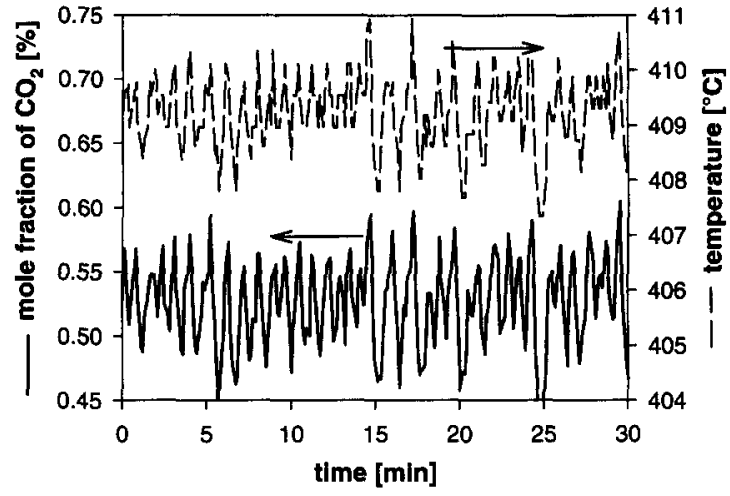

Fig. 9. Isothermal oscillations of the NO/CO reaction on diluted $\mathrm{Pt}-\mathrm{Mo} / \alpha-\mathrm{Al}_{2} \mathrm{O}_{3}$ catalyst powder ( $2 \% \mathrm{NO}, 1.1 \% \mathrm{CO}$ ).

amplitudes arose as depicted in Fig. 9. Amplitudes of temperature oscillations were only about $3 \mathrm{~K}$ and oscillations can be considered as "isothermal". The fact that isothermal oscillations can be found in this study excludes a thermokinetic origin of the oscillations and proofs that one has to do with kinetic oscillations.

The aperiodic character of the isothermal oscillations suggests a lack in the synchronisation of the elementary oscillators. Such a synchronisation is necessary to observe macroscopic oscillations of a reaction product. As synchronisation mechanisms temperature, concentration and surface diffusion are discussed. In another experiment $70 \%$ of the carrier gas argon was replaced by helium (helium has a ninefold higher heat conductivity as argon). This reduced the amplitude of $\mathrm{CO}_{2}$ oscillations and also of temperature oscillations to $25 \%$ of their original value. From this and from the aperiodic isothermal oscillations it must be concluded that mainly temperature variations serve as a synchronisation mechanism.

\subsection{Purge experiments}

Purge experiments were realised to clarify if changes of adsorbed species during oscillations and for stationary states take place.

During oscillations at $400^{\circ} \mathrm{C}$ they were stopped at different states by a sudden switch against pure Argon at $t=0$. Stopping the oscillations at the end of the upper operating state leads to curve a in Fig. 10. A comparison with the cumulative residence time distribution 


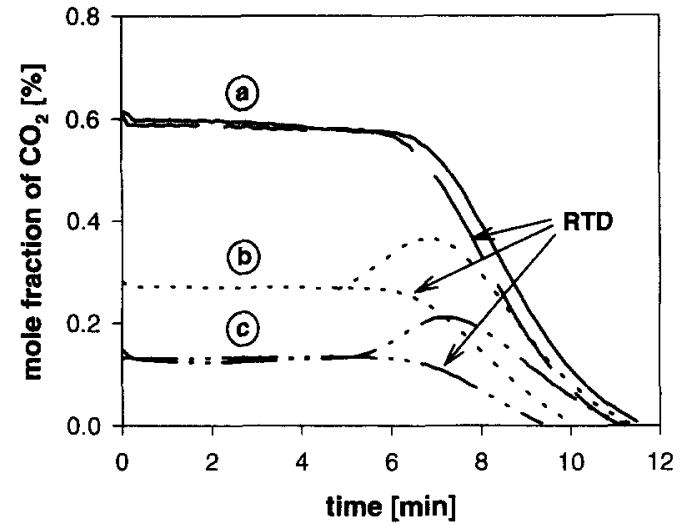

Fig. 10. Purge experiments for the oscillatory state at $400^{\circ} \mathrm{C}, 2 \%$ $\mathrm{NO}, 1 \% \mathrm{CO}$ and cumulative residence time distributions (RTD) of comparable $\mathrm{CO}_{2}$ concentrations. Purge experiments: $250 \mathrm{Nml} / \mathrm{min}$ reaction mixture was switched against $25 \mathrm{Nml} / \mathrm{min}$ pure argon at $t=0$ at: (a) end of upper operating state, (b) during ignition and (c) begin of lower operating state.

for the same $\mathrm{CO}_{2}$ concentration shows that no $\mathrm{CO}_{2}$ desorbs, thus no $\mathrm{CO}$ was adsorbed on the surface.

At the begin of the lower operating state one clearly notices a large amount of desorbing $\mathrm{CO}_{2}$ (curve $\mathrm{c}$ in Fig. 10), indicating previously adsorbed $\mathrm{CO}$ reacting with some oxygen of the lattice. During fast ignition (curve b) adsorbed $\mathrm{CO}$ was also present on the surface.

The same experiments were made for a stationary state. For the upper operating state no adsorbed $\mathrm{CO}$ was found whereas for the lower operating state a large amount of adsorbed $\mathrm{CO}$ was present. It must be concluded that the extinction of the reaction is closely connected to the fact that $\mathrm{CO}$ inhibits the reaction for high concentrations due to its strong adsorption (selfpoisoning).

\section{Discussion}

The described hysteresis in the CSTR can in principle be obtained by assuming a Langmuir-Hinshelwood kinetics (Eq. (4)), which passes a maximum if competitive adsorption of $\mathrm{NO}$ and $\mathrm{CO}$ on the same active sites occurs.

$$
R_{\mathrm{CO}_{2}}=k_{\mathrm{CO}_{2}} \Theta_{\mathrm{CO}} \Theta_{\mathrm{NO}}=\frac{k_{\mathrm{CO}_{2}} K_{\mathrm{NO}} p_{\mathrm{NO}} K_{\mathrm{CO}} p_{\mathrm{CO}}}{\left(1+K_{\mathrm{CO}} p_{\mathrm{CO}}+K_{\mathrm{NO}} p_{\mathrm{NO}}\right)^{2}} .
$$

With such a kinetic expression unique steady states should be obtained for all $\mathrm{CO}$ concentrations by raising the slope of the net inflow rate (increasing $\left.\dot{V} / m_{\text {cat }}\right)$ in Fig. 4 to a value where only one intersection point exists for each $\mathrm{CO}$ concentration. However, hysteresis was still present by diminishing the mass of the catalyst by a factor of 60 as demonstrated in Fig. 3. This indicates that the decrease is not a smooth one as in Fig. 4, which was modelled with Eq. (4), but much sharper. Consequently attempts of modelling all of the stationary values by such a kinetics failed and the decrease of the reaction rate was always too slow even with exponents of 3 or 4 in the denominator.

Moreover a Langmuir-Hinshelwood kinetics assuming adsorption equilibrium cannot yield oscillations in a tubular fixed-bed reactor as observed in this study [23]. A simple Langmuir-Hinshelwood kinetics can therefore be excluded.

To describe the behaviour in a more realistic way one has to require that the model is not only appropriate to describe the upper operating state, but also able to describe the sudden extinction to the lower operating state, which is only possible by including an autocatalytic step. To obtain kinetic oscillations it is also necessary to introduce a feedback mechanism into the model.

Several feedback mechanisms for oscillations in heterogeneous catalysis are proposed in literature, they were in general developed for the $\mathrm{CO} / \mathrm{O}_{2}$ reaction on single crystal planes. A proposed feedback mechanism has been the reconstruction of the surface structure $(1 \times 1 \Leftrightarrow h e x)$, reduction/oxidation of the catalyst or facetting.

A model which was developed by Fink et al. [24] uses an autocatalytic reaction mechanism combined with coverage-dependent activation energies for NO and $\mathrm{CO}$ adsorption to describe surface explosion of the $\mathrm{NO} / \mathrm{CO}$ reaction on $\mathrm{Pt}\left(\begin{array}{lll}1 & 0 & 0\end{array}\right)$ under ultra high-vacuum (UHV) conditions. Besides the surface explosion this model leads to oscillations of the $\mathrm{NO} / \mathrm{CO}$ reaction for certain conditions, where the coverage-dependent activation energies serve as a feedback mechanism [19]. The mechanism of the reaction is shown in Eqs. (5)-(8).

$$
\mathrm{CO}+\mathrm{Z} \underset{\mathrm{k}_{2}}{\stackrel{\mathrm{k}_{1}}{\rightleftarrows}} \mathrm{CO}-\mathrm{Z}
$$


$\mathrm{NO}+\mathrm{Z} \underset{\mathrm{k}_{4}}{\stackrel{\mathrm{k}_{3}}{\rightleftarrows}} \mathrm{NO}-\mathrm{Z}$

$\mathrm{NO}-\mathrm{Z}+\mathrm{Z} \stackrel{\mathrm{k}_{s}}{\rightarrow} \mathrm{N}-\mathrm{Z}+\mathrm{O}-\mathrm{Z}$

$\mathrm{CO}-\mathrm{Z}+\mathrm{O}-\mathrm{Z} \stackrel{\mathrm{k}_{6}}{\rightarrow} \mathrm{CO}_{2} \uparrow+2 \mathrm{Z}$

In this mechanism $\mathrm{Z}$ represents a free adsorption site and $\mathrm{X}-\mathrm{Z}$ an adsorbed species $\mathrm{X}$. Formed $\mathrm{N}-\mathrm{Z}$ during Eq. (7) is assumed to react immediately to form $\mathrm{N}_{2}$. To explain bistability one has to consider the sum of Eqs. (7) and (8), which leads to an autocatalytic step (Eq. (9)). If the dissociation of NO, which requires one free adsorption site is rate-limiting, the step in Eq. (9) accelerates the reaction since it leads to three free sites.

$\mathrm{NO}-\mathrm{Z}+\mathrm{CO}-\mathrm{Z}+\mathrm{Z} \rightarrow 0.5 \mathrm{~N}_{2} \uparrow+\mathrm{CO}_{2} \uparrow+3 \mathrm{Z}$

Such an autocatalytic step leads to a very fast extinction or ignition of the reaction, which can give rise to a bistability in a recycle loop reactor as the observed one. Nevertheless this mechanism leads up to now only to a fast ignition or extinction of the reaction in a tubular reactor, but not to oscillations.

To explain the observed oscillations in the tubular reactor, an additional feedback mechanism must be introduced into the model. This can be achieved with coverage dependant activation energies of desorption for NO and CO (Eq. (10)).

$$
\begin{aligned}
E_{\mathrm{des}, \mathrm{i}} & =E_{\mathrm{des}, \mathrm{i}}^{0}-k_{7}\left(\theta_{\mathrm{CO}}+\theta_{\mathrm{NO}}\right)^{n} \quad \text { with } n \\
& =1 \text { or } 2, \mathrm{i}=\mathrm{CO} \text { and } \mathrm{NO} .
\end{aligned}
$$

With this model oscillations arise in the following way:

Starting with a mixed $\mathrm{CO} / \mathrm{NO}$ adlayer, the high coverage inhibits NO dissociation and reaction rate is low (lower operating state). For a high coverage $E_{\text {des }}$ is low and desorption more favourable than adsorption. Desorption of some molecules creates a few vacant sites, where NO can dissociate and reaction rate increases slowly (slow ignition). Increasing number of vacant sites leads to a "surface explosion" because of the autocatalytic behaviour of the reaction (fast ignition). The burn-off leaves an almost bare surface at the end of the upper operating state; thus reaction rate decreases (fast extinction). During extinction the coverage dependant activation energy plays again an important role. For decreasing coverages $E_{\text {des }}$ gets larger and adsorption is facilitated, leading to the formation of a mixed CO/NO adlayer during extinction so that the cycle can start again.

This model has successfully been used to model surface explosion and oscillations on single crystal surfaces under UHV conditions [19]. The general form of the resulting oscillations (Fig. 14 in Ref. [19]) corresponds surprisingly well with the form of oscillations found in this study: slow ignition, fast ignition, upper operating state and fast extinction. This indicates that this model should be able to describe also the observed oscillations in this study. Such oscillations could in principle also arise in a recycle reactor, but in this study they are only observed in the tubular reactor, because they arise exactly in the region of instable states of the recycle loop reactor as was shown in Fig. 8.

Purge experiments described above were in agreement with the model and no adsorbed $\mathrm{CO}$ was found at the end of the upper operating state, indicating a "bare" surface as the model predicts. At the begin of the lower operating state as well as during ignition adsorbed $\mathrm{CO}$ was found, which is also in accordance with the model.

As the model does not imply any changes of the surface structure $(1 \times 1 \Leftrightarrow h e x)$ and the used assumptions are simple and realistic, it seems to be appropriate to describe all of the observed phenomena found in this study on a supported catalyst at atmospheric pressure. A problem for simulating the observed oscillations will be that for simplicity the reactor has to be modelled as a differential reactor. Low conversions $(0-40 \%)$ and small quantities of catalyst used $(0.017 \mathrm{~g}$ corresponding to six grains) which just covered the reactor cross-section area excludes large axial gradients of the bed and a modelling as differential reactor seems to be justifiable. One could still claim that oscillations are not isothermal and that one has to introduce a heat balance. Since temperature changes are not necessary as feedback mechanism of kinetic oscillations, it is not important to include the heat balance if one only wants to obtain a general oscillatory behaviour. On the other hand one has to include it if one attempts to model amplitude and frequency of the oscillations quantitatively. 


\section{Conclusions}

For the $\mathrm{NO} / \mathrm{CO}$ reaction on a $0.5 \% \mathrm{Pt}-3.4 \%$ $\mathrm{MoO}_{3}$ catalyst supported on $\alpha-\mathrm{Al}_{2} \mathrm{O}_{3}$ bistability in a recycle loop reactor and non-isothermal kinetic oscillations in a tubular reactor are found at atmospheric pressure. The oscillations arise exactly in the region where instable states are obtained for the recycle reactor and therefore oscillations cannot be observed in this type of reactor. The characteristics of the observed oscillations fit to findings of other authors [17]. A model developed by Fink et al. [19] to describe the surface explosion of $\mathrm{NO} / \mathrm{CO}$ on $\mathrm{Pt}\left(\begin{array}{lll}1 & 0 & 0\end{array}\right)$ under UHV conditions was discussed and can explain the observed experimental phenomena. The model contains two important qualities: Firstly the model has an autocatalytic step, which leads to very abrupt onset or extinction of the reaction thus to bistability and hysteresis phenomena for a recycle loop reactor. Secondly the activation energies for desorption decrease with increasing coverages, thus serving as a feedback mechanism which is a necessary condition for oscillations. Consequently this model is appropriate to describe bistability as well as oscillations. First hints to the correctness of the model are given by purge experiments. Further efforts will be undertaken to apply the model to the present system where oscillations occur at higher temperatures and concentrations.

\section{Acknowledgements}

Financial support by the Swiss National Science Foundation is gratefully acknowledged.

\section{References}

[1] I.R. Epstein, K. Kustin, P. De Kepper, M. Orbán, in: Digest: Moderne Chemie/, Spektrum der Wissenschaft, Spektrum der Wissenschaft Verlagsgesellschaft, Heidelberg/Juni 1995, p. 28.

[2] P. Gray, S.K. Scott, Chemical Oscillations and Instabilities, Clarendon Press, Oxford, 1990, p. 182.

[3] T. Matsuura and M. Kato, Chem. Eng. Sci., 22 (1967) 171.

[4] G. Eigenberger, Chem.-Ing.-Techn., 50 (1978) 924.

[5] H. Beusch, P. Fieguth and E. Wicke, Chem.-Ing.-Techn., 44 (1972) 445 .

[6] E. Wicke, Chem.-Ing.-Techn., 46 (1974) 365.

[7] P. Hugo and M. Jakubith, Chem.-Ing.-Techn., 44 (1972) 383.

[8] G. Ertl, Adv. Catal., 37 (1990) 213.

[9] M.M. Slin'ko and N.I. Jaeger, Stud. Surf. Sci. Catal., 86 (1994) 10.

[10] S.P. Singh-Boparai, D.A. King,/Proc. 4th Int. Conf. on Solid Surfaces and 3rd Europ. Conf. on Surface Science, Cannes/ 22-26 September 1980, in: Le vide, les Couches Minces, No. 201, Suppl. 1/1.

[11] W. Adlhoch, H.-G. Lintz and T. Weisker, Surf. Sci., 103 (1981) 576.

[12] B. Subramaniam and A. Varma, Chem. Eng. Commun., 21 (1983) 221.

[13] S.B. Schwartz and L.D. Schmidt, Surf. Sci., 206 (1988) 169.

[14] H. Bolten, T. Hahn, J. LeRoux and H.-G. Lintz, Surf. Sci. Lett., 160 (1985) L529.

[15] J. Regalbuto and E.E. Wolf, Chem. Eng. Commun., 41 (1986) 315.

[16] S.B. Schwartz and L.D. Schmidt, Surf. Sci., 183 (1987) L269.

[17] F. Schüth and E. Wicke, Ber. Bunsenges. Phys. Chem., 93 (1989) 191.

[18] L.D. Schmidt, R. Aris, in: Yu.Sh. Matros (Ed.), Unsteady State Processes in Catalysis, VSP, Utrecht, 1990, p. 203.

[19] Th. Fink, J.-P. Dath, R. Imbihl and G. Ertl, J. Chem. Phys., 95 (1991) 2109.

[20] G. Veser and R. Imbihl, J. Chem. Phys., 100 (1994) 8492.

[21] R. Imbihl and G. Veser, J. Vac. Sci. Technol. A, 12 (1994) 2170.

[22] M. Baerns, H. Hofmann, A. Renken, Chemische Reaktionstechnik, Georg Thieme Verlag, Stuttgart, 1990, p. 146.

[23] G. Eigenberger, Chem. Eng. Sci., 33 (1978) 1255.

[24] Th. Fink, J.-P. Dath, M.R. Bassett, R. Imbihl and G. Ertl, Surf. Sci., 245 (1991) 96. 